\title{
A study on predictors of treatment outcome among children registered under DOTS in district Tarn Taran, Punjab \\ Pooja Sadana ${ }^{1}$, Vishal Verma², Manisha Nagpal ${ }^{3}$
}

${ }^{1}$ Associate professor, Department of Community Medicine, Sri Guru Ram Das Institute of Medical Sciences and Research, Sri Amritsar; ${ }^{2}$ District TB Officer, Tarn Taran, Punjab; ${ }^{3}$ Professor, Department of Community Medicine, Sri Guru Ram Das Institute of Medical Sciences and Research, Sri Amritsar

\begin{tabular}{|c|c|c|c|c|c|c|c|c|}
\hline Abstract & Introduction & Methodology & Results & Conclusion & $\underline{\text { References }}$ & Citation & \multicolumn{2}{|c|}{ Tables / Figures } \\
\hline \multicolumn{9}{|c|}{ ing Author } \\
\hline \multicolumn{8}{|c|}{$\begin{array}{l}\text { Dr Pooja Sadana, Associate professor, Department of Community Medicine, Sri Guru Ram Das Institute of } \\
\text { Medical Sciences and Research, Sri Amritsar, Punjab } 143501 \\
\text { E Mail ID: sadanapooja@hotmail.com }\end{array}$} & 回语回 \\
\hline
\end{tabular}

\section{Citation}

Sadana P, Verma V, Nagpal M. A study on predictors of treatment outcome among children registered under DOTS in district Tarn Taran, Punjab. Indian J Comm Health. 2020;32(2):399-403.

Source of Funding: Nil Conflict of Interest: None declared

\section{Article Cycle}

Received: 18/04/2020; Revision: 07/05/2020; Accepted: 07/06/2020; Published: 30/06/2020

This work is licensed under a Creative Commons Attribution 4.0 International License.

\section{Abstract}

Background: Globally, tuberculosis remains an important cause of morbidity and mortality for children. Diagnosis and management of childhood TB especially Extra pulmonary tuberculosis is challenging. Method: A cross-sectional study was conducted on 0-14 year children who were registered and being treated, in district Tarn Taran, Punjab from 1st January 2018 to 31st December 2018. The treatment outcome with their clinico-demographic determinants was ascertained. Data management and analysis was done by using Microsoft excel and SPSS. Results: Out of 62 registered patients, $62.9 \%$ of the children were in age group of $11-14$ years. $67.7 \%$ were females. The various treatment outcomes observed were-cured $32.3 \%$, treatment completed $61.3 \%$, lost to follow up $1.6 \%$, regimen changed $1.6 \%$, not evaluated $3.2 \%$. The success rate (cured+ treatment completed) was $93.6 \%$. On statistical analysis, it was observed that age $(p=0.002)$, site of disease $(p=0.000)$, contact history $(p=0.012)$ and diagnostic method $(0.000)$ was significantly associated with the treatment outcome whereas gender, area of residence and type of case had no association with the treatment outcome in children. Conclusions: We also found that the overall treatment success rate was $93.6 \%$. Increased focus be on those with household contact with TB.

\section{Keywords}

Tuberculosis; Children; Predictors; Treatment outcome

\section{Introduction}

Though Tuberculosis is a preventable and curable disease, it continues to devastate the lives of millions of children. Worldwide in 2018, about 1 million cases of tuberculosis disease and 233000 tuberculosis-related deaths occurred among children younger than 15 years. (1) Ninety-six percent of children die from TB before the start of treatment.(2)

Overall $55 \%$ of estimated children with TB (0-14 years) are not reported to national TB programmes. TB reporting gap is $69 \%$, which is biggest among children less than 5 year, as compared to $35 \%$ gap in reporting in all age groups combined. (3) Accurate statistics on pediatric TB cases are difficult to obtain for a multitude of reasons, including under-recognition, challenges in confirming the diagnosis, and under-reporting to national TB programme. This leads to delay in initiating appropriate treatment and have implications on child morbidity and mortality. (4) Children under 5 years are also more likely to progress to tuberculosis disease after infection, and have the highest rates of severe, disseminated forms of tuberculosis compared with older age groups. (5) Children with latent infection become the reservoir for future transmission following disease reactivation in adulthood, fueling future epidemics. Considering that TB in children serves as a marker for recent disease transmission therefore, it is important to have a good understanding of the burden of childhood TB and risk factors for poor treatment outcome.(6)

\section{Aims \& Objectives}

1. To determine the treatment outcome among children with TB registered under DOTS in district Tarn Taran 
2. To determine the relationship of demographic and clinical factors with treatment outcome in childhood TB.

\section{Material \& Methods}

Study type: Cross-sectional study

Study Population and Area: Children aged 0-14 years registered with District Tuberculosis Centre, Tarn Taran

Study Duration: 1st January 2018 to 31st December 2018. Inclusion criteria: All children in the age group of 0-14 year after informed consent from the parents/guardian.

Exclusion criteria: Critically ill children and those with multi drug resistant tuberculosis were excluded from the study.

\section{Data collection and analysis}

The study was conducted in Tarn Taran district of Punjab having the total population of $11,59,858$ out of which 97,822 is rural and 1,81636 is urban. A total of 1218 patients were registered with District Tuberculosis Centre, Tarn Taran for year 2018. Of all the registered patients, 62 children with confirmed drug-susceptible TB were enrolled for the study. List of patients and their treatment record was collected from District Tuberculosis Officer, Tarn Taran. Houses of all the patients were located using information available from the tuberculosis register and DOT providers. The parent or the guardian was informed about the purpose of the study and their consent was taken in their own vernacular language. A pre-designed and pre -tested proforma was administered to the subjects. Questionnaire included questions regarding the socio-demographic and clinical profile of the patients. Data including types of TB, method of diagnosis, HIV and diabetes status and treatment outcomes was obtained from the patient's medical records and from TB register.

Criteria for patient treatment outcome were determined according to RNTCP guidelines. (7) The possible outcomes of the drug susceptible TB patients under DOTS can be: cured, treatment completed, failure, Failure to respond, regimen changed and died.

Cured: Microbiologically confirmed TB patient at the beginning of treatment who was smear Or culture negative at the end of the complete treatment.

Treatment completed: A TB patient who completed treatment without evidence of failure or clinical deterioration BUT with no record to how that sputum smear or culture results of biological specimen in the last month of treatment was negative, either because tests were not done or because results are unavailable.

Failure: A TB patient whose biological specimen is positive by smear or culture at the end of treatment.

Failure to respond: A case of paediatric TB who fails to have microbiological conversion to negative status or fails to respond clinically/or deteriorates after 12 weeks of compliant treatment shall be deemed to have failed response provided alternative diagnosis/reasons for nonresponse have been ruled out.
Lost to follow up: A TB patient whose treatment was interrupted continuously for ONE month or more.

Not evaluated: A TB patient for whom no treatment outcome is assigned. This includes former "transfer-out". Treatment Regimen changed: A TB patient who is on first line regimen and has been diagnosed as having Drug resistant $T B$ and switched to drug resistant $T B$ regimen prior to being declared as failed.

Died: A patient who has died during the course of treatment.

Ethical Approval: Taken from the institutional ethical committee at the time of commencement of the study.

Statistical analysis: Data was tabulated on Microsoft Excel Sheet. The master chart was prepared and data analysis was carried out by using SPSS 22.0 version. The demographic and clinical variables were analysed by frequency and percentage. Chi square test was used was used to evaluate differences in categorical variables and $p<0.05$ was considered to be significant.

\section{Results}

The present study assessed the treatment outcomes and determinants among children, registered under DOTS program in District Tarn Taran. Table 1 depicts that out of total 62 cases, more than half i.e. $62.9 \%$ were $10-14$ years of age. Female predominance was seen, with female to male ratio of $2: 1$. Of the total study subjects, $72.6 \%$ were from rural background. As far as site of TB is concerned, both pulmonary and extra-pulmonary cases were equal in number. Majority i.e. 91.9\%; were new TB cases. It was revealed that $25.8 \%$ children had history of contact with some TB patient and rest had no contact history. Out of the total, $38.7 \%$ of the patients were diagnosed by $\mathrm{ZN}$ microscopy, $17.7 \%$ by Chest X-ray, $6.5 \%$ by CBNAAT and $37.1 \%$ by other diagnostic tests. Regarding HIV status only 1 case was found to be HIV positive. Of all the children, $3.2 \%$ were diabetic and $14.5 \%$ patients did not get themselves evaluated for diabetes. (Table 1)

The perusal of table shows that out of the total 62 patients, $20(32.3 \%)$ were cured, 38 (61.3\%) completed treatment, 1 each was lost to follow up and changed regimen and for 2 (3.2\%) the outcome was not evaluated.(Table 2)

Table 3 reveals that among different demographic and clinical factors, age $(p=0.002)$, mode of diagnosis $(p=0.000)$, site of TB $(p=0.000)$ and contact history $(p=0.012)$ were significantly associated with the treatment outcome whereas sex and area of residence and type of case had no such association.(Table 3 )

\section{Discussion}

A total of 62 pediatric patients were registered under DOTS in District Tarn Taran and were enrolled in the study. In the present study, maximum number of patients (62.9\%) were in age group of $11-14$ year, which is in agreement with the 
previous studies done in Ethiopia by Hailu et al and Tilahun \& Gebre-Selassie. $(8,9)$ Similar findings were also reported by Bharani A et al from central India.(10) In our study children under the age of 5 years constituted only $16.1 \%$ of total childhood TB cases despite the fact that childhood TB is commonest in the age group of $<5$ years. (3) The most reasonable explanation can be difficulties in the diagnosis of younger children, principally in collecting bacteriologic specimens or gastric aspirates which can result in under reporting of TB cases in this age group. $(11,12)$

In the present study, participants constituted more of the females (67.7\%) as compared to the males. These findings are similar to a study done by Mazta et al. (13) Many of the Indian studies found that more than $60 \%$ of those affected with childhood TB were females. (14) One possible reason for higher number of girls affected could be neglect of girl child leading to poor nutritional status, consequently low immunity and poor treatment seeking behavior of parents .

Our study revealed that $72.6 \%$ of the participants resided in the rural areas and an equal number of children were diagnosed with Pulmonary and Extra pulmonary Tuberculosis. This could be due to small sample size of the present study.

Present study revealed that $91.9 \%$ subjects were registered as new cases. Study by laghari et al had $95.5 \%$ children enrolled as new cases. (15) In another study by Ogbudebe et al, a high proportion of patients (98.5\%) had new TB infection.(16)

In the present study, the majority of children were diagnosed by sputum microscopy (38.7\%) followed by other tests like CT scan, FNAC and Ultrasonography for diagnosing Extra pulmonary tuberculosis. Study by Ogbudebe et al showed that nearly a third (27.8\%) were bacteriologically diagnosed, whereas rest were diagnosed clinically. (16)

A Perusal of table 2 shows the treatment outcomes of patients. In the present study, the overall treatment success rate (cured+ Treatment completed) was 93.6\%, similar results were documented in their studies by Laghari et al. (17)

(Table 3) illustrates that age $(p=0.002)$, site of disease $(p=0.000)$, contact history $(p=0.012)$ and diagnostic method (0.000) was significantly associated with the treatment outcome whereas gender, area of residence and type of case had no association with the treatment outcome in children.

Similar findings were observed in the study by Laghari et al and Ramesh et al that age is significantly associated with treatment outcome. $(15,18)$ Similarly study by Ogbudebe LC et al found that site, type of TB and diagnostic method were the factors significantly associated with the treatment outcome.(16) Other studies by Alavi et al and Laghari $\mathrm{M}$ et al revealed that contact history of the child was significantly associated with the treatment outcome. $(19,15)$

\section{Conclusion}

The present study had success rate of $93.6 \%$ which is in more than the national success rate. Our study also revealed that most of the patients were in the age group of 6-14 years. Age, site of disease, contact history and diagnostic method was significantly associated with the treatment outcome.

\section{Recommendation}

To improve the identification of TB in children, household contact investigation of all TB patients should be systematically implemented in children. Routine screening of TB should be intensified among children to improve TB treatment outcome. Further studies are needed to assess the reasons for the low proportion of TB case notification among the under five children. We need to identify and implement strategies to reach out to the cases missed by the programme and address challenges in reaching all childhood TB patients.

\section{Authors Contribution}

PS: Study design; VV: Data collection and MN: Data analysis. All the authors have contributed in writing and reviewing of the manuscript.

\section{References}

1. WHO. Global tuberculosis report 2018. Available at https://www.who.int/tb/publications/global report/en/

2. Dodd PJ, Yuen CM, Sismanidis C, Seddon JA, Jenkins HE. The global burden of tuberculosis mortality in children: a mathematical modelling study. Lancet Glob Health. 2017 Sep;5(9):e898-e906. doi: 10.1016/S2214-109X(17)30289-9. PubMed PMID: 28807188; PubMed Central PMCID: PMC5556253.[PubMed]. doi: 10.1016/S2214-109X(17)30289-9.

3. WHO. Roadmap towards ending TB in children and adolescents. Geneva: World Health Organization 2018. Available at https://apps.who.int/iris/bitstream/handle/10665/274374/97892 41514668-eng.pdf Accessed on 11/3/ 2020.

4. Thomas TA. Tuberculosis in Children. Pediatr Clin North Am. 2017 Aug;64(4):893-909. doi: 10.1016/j.pcl.2017.03.010. Review. PubMed PMID: 28734517; PubMed Central PMCID: PMC5555046.[PubMed].

5. Cowger TL, Wortham JM, Burton DC. Epidemiology of tuberculosis among children and adolescents in the USA, 2007-17: an analysis of national surveillance data. Lancet Public Health. 2019 Oct;4(10):e506-e516. doi: 10.1016/\$2468-2667(19)30134-3. Epub 2019 Aug 21. PubMed PMID: 31446052. [PubMed].

6. John TJ. Tuberculosis control in India: why are we failing?. Indian Pediatr. 2014 Jul;51(7):523-7. doi: 10.1007/s13312-014-0440-x. PubMed PMID: 25031127. [PubMed].

7. Revised National Tuberculosis Control Programme. Training Course for medical officers and TB program managers. Modules 1 4: Central TB Division, Directorate General of Health Sciences, Ministry of Health and Family Welfare, New Delhi. 2019:152.

8. Hailu D, Abegaz WE, Belay M. Childhood tuberculosis and its treatment outcomes in Addis Ababa: a 5-years retrospective study. BMC Pediatr. 2014 Mar 3;14:61. doi: 10.1186/1471-2431-14-61. PubMed PMID: 24581267; PubMed Central PMCID: PMC3944801.[PubMed].

9. Tilahun G, Gebre-Selassie S. Treatment outcomes of childhood tuberculosis in Addis Ababa: a five-year retrospective analysis. BMC Public Health. 2016 Jul 21;16:612. doi: 10.1186/s12889-016-31938. PubMed PMID: 27443308; PubMed Central PMCID: PMC4957362.[PubMed]. 
INDIAN JOURNAL OF COMMUNITY HEALTH / VOL 32 / ISSUE NO 02 / APR - JUN 2020

10. Bharani A, Harshey M, Raipurkar S. Profile and outcome of childhood tuberculosis treated with DOTS at a tertiary care hospital in central India: an observational study. Int J Contemp Pediatr. 2018; 5: 324-7.

11. Marais BJ, Hesseling AC, Gie RP, Schaaf HS, Enarson DA, Beyers N. The bacteriologic yield in children with intrathoracic tuberculosis. Clin Infect Dis. 2006 Apr 15;42(8):e69-71. doi: 10.1086/502652. Epub 2006 Mar 6. PubMed PMID: 16575719.[PubMed].

12. Planting NS, Visser GL, Nicol MP, Workman L, Isaacs W, Zar HJ. Safety and efficacy of induced sputum in young children hospitalised with suspected pulmonary tuberculosis. Int J Tuberc Lung Dis. 2014 Jan;18(1):8-12. doi: 10.5588/ijtld.13.0132. PubMed PMID: 24365546.[PubMed].

13. Mazta SR, Kumar A, Kumar P. Demographic Profile of Childhood TB Cases under Revised National Tuberculosis Control Program in Himachal. Bangalore: National Tuberculosis Institute Bulletin. 2014. http://tbresearch.ntiindia.org.in/id/eprint/1628.

14. Dhaked S, Sharma N, Chopra KK, Khanna A, Kumar R. Sociodemographic profile and treatment outcomes in pediatric TB patients attending DOTS centers in urban areas of Delhi. Indian J Tuberc. 2019 Jan;66(1):123-128. doi: 10.1016/j.ijtb.2018.06.006. Epub 2018 Jul 12. PubMed PMID: 30797269.[PubMed].

15. Laghari M, Sulaiman SAS, Khan AH, Memon N. A prospective study of socio-demographic, clinical characteristics and treatment
[Predictors of treatment ...] | Sadana P et al outcomes of children with tuberculosis in Sindh, Pakistan. BMC Infect Dis. 2019 Jan 24;19(1):82. doi: 10.1186/s12879-019-3702-3. PubMed PMID: 30678656; PubMed Central PMCID: PMC6345030.[PubMed].

16. Ogbudebe CL, Adepoju V, Ekerete-Udofia C, Abu E, Egesemba G, Chukwueme N, Gidado M. Childhood Tuberculosis in Nigeria: Disease Presentation and Treatment Outcomes. Health Serv Insights. 2018;11:1178632918757490. doi: 10.1177/1178632918757490. eCollection 2018. PubMed PMID: 29511357; PubMed Central PMCID: PMC5826094.[PubMed].

17. Laghari M, Sulaiman SAS, Khan AH, Memon N. Epidemiology of tuberculosis and treatment outcomes among children in Pakistan: a 5 year retrospective study. PeerJ. 2018;6:e5253. doi: 10.7717/peerj.5253. eCollection 2018. PubMed PMID: 30065869; PubMed Central PMCID: PMC6065458.[PubMed]

18. Ramesh, Shobha A, Manjula VD. Treatment Outcomes of Childhood Tuberculosis with Dots Strategy in Kottayam, Kerela. Indian J Community Health. 2012; 24(4):280-4.

19. Alavi SM, Salmanzadeh S, Bakhtiyariniya P, Albagi A, Hemmatnia F, Alavi L. Prevalence and treatment outcome of pulmonary and extrapulmonary pediatric tuberculosis in southwestern Iran. Caspian J Intern Med. 2015 Fall;6(4):213-9. PubMed PMID: 26644895; PubMed Central PMCID: PMC4649270.[PubMed]

\section{Tables}

TABLE 1 DISTRIBUTION OF PATIENTS ACCORDING TO DEMOGRAPHIC AND CLINICAL VARIABLES

\begin{tabular}{|c|c|c|}
\hline \multirow{2}{*}{\multicolumn{3}{|c|}{$\begin{array}{l}\text { Socio-demographic factor } \\
\text { Age Group (years) }\end{array}$}} \\
\hline & & \\
\hline $0-5$ & 10 & 16.1 \\
\hline $6-10$ & 13 & 21.0 \\
\hline $11-14$ & 39 & 62.9 \\
\hline \multicolumn{3}{|l|}{ Sex } \\
\hline Male & 20 & 32.3 \\
\hline Female & 42 & 67.7 \\
\hline \multicolumn{3}{|l|}{ Area of Residence } \\
\hline Rural & 45 & 72.6 \\
\hline Urban & 17 & 27.4 \\
\hline \multicolumn{3}{|l|}{ Site } \\
\hline Pulmonary & 31 & 50.0 \\
\hline Extra-pulmonary & 31 & 50.0 \\
\hline \multicolumn{3}{|l|}{ Type of Case } \\
\hline New treatment regimen & 57 & 91.9 \\
\hline Retreatment regimen & 5 & 8.1 \\
\hline \multicolumn{3}{|l|}{ Contact history } \\
\hline Present & 16 & 25.8 \\
\hline Absent & 46 & 74.2 \\
\hline \multicolumn{3}{|l|}{ Diagnosis } \\
\hline Microscopy (ZN staining) & 24 & 38.7 \\
\hline Chest X Rays & 11 & 17.7 \\
\hline Others & 23 & 37.1 \\
\hline CBNAAT & 4 & 6.5 \\
\hline \multicolumn{3}{|l|}{ HIV status } \\
\hline Non-Reactive & 61 & 98.4 \\
\hline Reactive & 1 & 1.6 \\
\hline \multicolumn{3}{|l|}{ Co-morbidity } \\
\hline Diabetic & 2 & 3.2 \\
\hline Non-diabetic & 51 & 82.3 \\
\hline Not-known & 9 & 14.5 \\
\hline
\end{tabular}




\begin{tabular}{|l|l|l|}
\hline TABLE 2 DISTRIBUTION OF CASES & ACCORDING TO THEIR TREATMENT OUTCOME \\
\hline \begin{tabular}{l|l} 
Outcome \\
Cured
\end{tabular} & Frequency & Percentage \\
\hline Treatment completed & 20 & 32.3 \\
\hline Lost to Follow Up & 38 & 61.3 \\
\hline Regimen changed & 1 & 1.6 \\
\hline Not evaluated & 1 & 1.6 \\
\hline
\end{tabular}

TABLE 3 DISTRIBUTION OF CASES SHOWING THE DEMOGRAPHIC AND CLINICAL FACTORS AFFECTING THE TREATMENT OUTCOME

\begin{tabular}{|c|c|c|c|c|c|c|}
\hline \multirow{3}{*}{ Characteristics of patient } & \multicolumn{5}{|c|}{ Treatment Outcome } & \multirow[t]{3}{*}{ Significance } \\
\hline & Cured & $\begin{array}{l}\text { Treatment } \\
\text { Completed }\end{array}$ & \multirow{2}{*}{$\begin{array}{l}\text { Lost to } \\
\text { follow up } \\
(N=1) N(\%)\end{array}$} & $\begin{array}{l}\text { Regimen } \\
\text { Changed }\end{array}$ & \multirow{2}{*}{$\begin{array}{l}\text { Not } \\
\text { Evaluated } \\
(\mathrm{N}=2) \mathrm{N}(\%)\end{array}$} & \\
\hline & $(N=20) N(\%)$ & $(N=38) N(\%)$ & & $(N=1) N(\%)$ & & \\
\hline \multicolumn{7}{|l|}{ Age (years) } \\
\hline $0-5(n=10)$ & $0(0)$ & $10(100)$ & $0(0)$ & $0(0)$ & $0(0)$ & $\chi 2=24.415$ \\
\hline $6-10(n=13)$ & $1(7.7)$ & $9(69.2)$ & $0(0)$ & $1(7.7)$ & $2(15.4)$ & $d f=8$ \\
\hline $11-14(n=39)$ & $19(48.7)$ & $19(48.7)$ & $1(2.6)$ & $0(0)$ & $0(0)$ & $p=0.002$ \\
\hline \multicolumn{7}{|l|}{ Sex } \\
\hline \multirow[t]{2}{*}{ Male $(n=20)$} & \multirow[t]{2}{*}{$3(15.0)$} & \multirow[t]{2}{*}{$15(75.0)$} & \multirow[t]{2}{*}{$1(5.0)$} & \multirow[t]{2}{*}{$1(5.0)$} & \multirow[t]{2}{*}{$0(0)$} & $\chi 2=8.784$ \\
\hline & & & & & & $d f=4$ \\
\hline Female $(n=42)$ & $17(40.5)$ & $23(54.8)$ & $0(0)$ & $0(0)$ & $2(4.8)$ & $p=0.06$ \\
\hline \multicolumn{7}{|l|}{ Area of Residence } \\
\hline \multirow[t]{2}{*}{ Rural ( $n=45)$} & \multirow[t]{2}{*}{$15(33.3)$} & \multirow[t]{2}{*}{$27(60.0)$} & \multirow[t]{2}{*}{$1(2.2)$} & \multirow[t]{2}{*}{$0(0)$} & \multirow[t]{2}{*}{$2(4.4)$} & $\chi 2=3.884$ \\
\hline & & & & & & $d f=4$ \\
\hline Urban $(n=17)$ & $5(29.4)$ & $11(64.7)$ & $0(0)$ & $1(5.9)$ & $0(0)$ & $p=0.422$ \\
\hline \multicolumn{7}{|l|}{ Contact History } \\
\hline \multirow[t]{2}{*}{ Present(n=16) } & \multirow[t]{2}{*}{$3(18.8)$} & \multirow[t]{2}{*}{$9(56.3)$} & \multirow[t]{2}{*}{$1(6.3)$} & \multirow[t]{2}{*}{$1(6.3)$} & \multirow[t]{2}{*}{$2(12.5)$} & $\chi 2=12.809$ \\
\hline & & & & & & $d f=4$ \\
\hline Absent(n=46) & $17(37.0)$ & $29(63.0)$ & $0(0)$ & $0(0)$ & $0(0)$ & $p=0.012$ \\
\hline \multicolumn{7}{|l|}{ Diagnosis } \\
\hline ZN Microscopy $(n=24)$ & $18(75.0)$ & $5(20.8)$ & $1(4.2)$ & $0(0)$ & $0(0)$ & $\chi 2=39.021$ \\
\hline Chest X Ray (n=11) & $1(9.1)$ & $9(81.8)$ & $0(0)$ & $0(0)$ & $1(9.1)$ & $d f=12$ \\
\hline Others $(n=23)^{*}$ & $0(0)$ & $21(91.3)$ & $0(0)$ & $1(4.3)$ & $1(4.3)$ & $p=0.000$ \\
\hline CBNAAT $(n=4)^{* *}$ & $1(25.0)$ & $3(75.0)$ & $0(0)$ & $0(0)$ & $0(0)$ & \\
\hline \multicolumn{7}{|l|}{ Site } \\
\hline \multirow[t]{2}{*}{ Pulmonary $(n=31)$} & $20(64.5)$ & $10(32.3)$ & $1(3.2)$ & $0(0)$ & $0(0)$ & $\chi 2=32.526$ \\
\hline & & & & & & $d f=4$ \\
\hline Extra-pulmonary $(n=31)$ & $0(0)$ & $28(90.3)$ & $0(0)$ & $1(3.2)$ & $2(6.5)$ & $p=0.000$ \\
\hline Type of Case & & & & & & \\
\hline New $(n=57)$ & $18(31.6)$ & $35(61.4)$ & $1(1.8)$ & $1(1.8)$ & $2(3.5)$ & $\chi 2=0.453$ \\
\hline & & & & & & $d f=4$ \\
\hline Retreatment $(n=5)$ & $2(40.0)$ & $3(60.0)$ & $0(0)$ & $0(0)$ & $0(0)$ & $p=0.978$ \\
\hline
\end{tabular}

